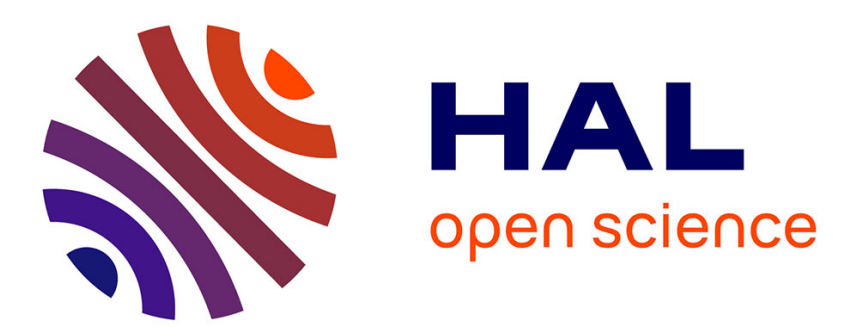

\title{
Shape resonances in vibrational excitation of molecules : [100] symmetric stretch mode excitation in CO2
}

\author{
M. Tronc, R. Azria, R. Paineau
}

\section{To cite this version:}

M. Tronc, R. Azria, R. Paineau. Shape resonances in vibrational excitation of molecules: [100] symmetric stretch mode excitation in CO2. Journal de Physique Lettres, 1979, 40 (14), pp.323-324. 10.1051/jphyslet:019790040014032300 . jpa-00231635

\section{HAL Id: jpa-00231635 https://hal.science/jpa-00231635}

Submitted on 1 Jan 1979

HAL is a multi-disciplinary open access archive for the deposit and dissemination of scientific research documents, whether they are published or not. The documents may come from teaching and research institutions in France or abroad, or from public or private research centers.
L'archive ouverte pluridisciplinaire HAL, est destinée au dépôt et à la diffusion de documents scientifiques de niveau recherche, publiés ou non, émanant des établissements d'enseignement et de recherche français ou étrangers, des laboratoires publics ou privés. 


\title{
Shape resonances in vibrational excitation of molecules : [100] symmetric stretch mode excitation in $\mathrm{CO}_{2}$
}

\author{
M. Tronc, R. Azria and R. Paineau \\ Laboratoire des Collisions Atomiques et Moléculaires (*), \\ Université de Paris-Sud, Bât. 351, 91405 Orsay Cedex, France
}

(Reçu le 23 avril 1979, accepté le 29 mai 1979)

\begin{abstract}
Résumé. - La section efficace différentielle d'excitation vibrationnelle résonnante du mode d'élongation symétrique [100] de $\mathrm{CO}_{2}$ est obtenue entre 1 et $35 \mathrm{eV}$. A côté de la résonance de forme bien connue de symétrie $\pi_{\mathrm{u}}$ et centrée à $3,8 \mathrm{eV}$, on observe deux nouvelles structures résonnantes très larges et de faible intensité. Ces structures centrées respectivement à $10,8 \mathrm{eV}$ et $30 \mathrm{eV}$ sont attribuées à des résonances de forme de symétrie $\sigma_{\mathrm{g}}$ et $\sigma_{\mathrm{u}}$ prévues par de récents calculs théoriques de Dehmer et Dill utilisant la méthode de diffusion multiple.
\end{abstract}

\begin{abstract}
The differential cross-section for vibrational excitation of the [100] symmetric stretch mode in $\mathrm{CO}_{2}$ is obtained in the 1-35 eV energy range. Besides the well known $\pi_{\mathrm{u}}$ shape resonance at $3.8 \mathrm{eV}$, two new resonance structures with low intensities and large widths are observed. These structures centred at 10.8 and $30 \mathrm{eV}$ are attributed to $\sigma_{\mathbf{g}}$ and $\sigma_{\mathrm{u}}$ shape resonances respectively, as predicted by theoretical continuum multiple-scattering calculations by Dehmer and Dill.
\end{abstract}

1. Introduction. - Shape resonances are well known for the enhancement of vibrational excitation cross-sections at low energy $(0-5 \mathrm{eV})$ [1]. These resonances are observed in electron scattering when the interaction potential between the incident electron and a molecule produces a centrifugal barrier resulting from the balance between centrifugal and electrostatic forces. The electron is trapped behind the centrifugal barrier to produce a short-lived negative ion, and escapes by tunneling through the barrier. Recently the role of centrifugal barriers has been shown, both theoretically $[2,3]$ and experimentally $[4,5]$ to be dominant in the excitation of inner-shell electrons to discrete states and in photoionization [3].

A continuum multiple-scattering approach to electron molecule scattering [3] predicts the existence of broad shape resonances characterized by phaseshift increasing by less than $\pi$ radians over several volts at high energies $(10-50 \mathrm{eV})$. These very short-lived resonances are difficult to observe in elastic and total cross-sections because of the presence of the dominant direct process. But they can be observed in vibrational excitation cross-section as the direct process is practically not observed at high energies [3].

(*) Laboratoire associé au C.N.R.S
2. Experimental method. - We have used an electron spectrometer made of two electrostatic filters to measure differential cross-sections in electron scattering after interaction with a target gas beam crossing the incident electron beam at right angles. This apparatus has been already used for resonant vibrational excitation in $\mathrm{NO}$ [6], $\mathrm{CO}_{2}$ [7] and $\mathrm{SO}_{2}$ [8] at low energies. The overall resolution was $50 \mathrm{meV}$, so that the first fundamental vibrational modes in $\mathrm{CO}_{2}$ were resolved. The energy scale of figure 1 was obtained by observing the $1 \mathrm{~s} 2 \mathrm{p}^{2}{ }^{2} \mathrm{~S}$ resonance in the elastic scattering of helium at $19.36 \mathrm{eV}$ in a $\mathrm{CO}_{2}+\mathrm{He}$

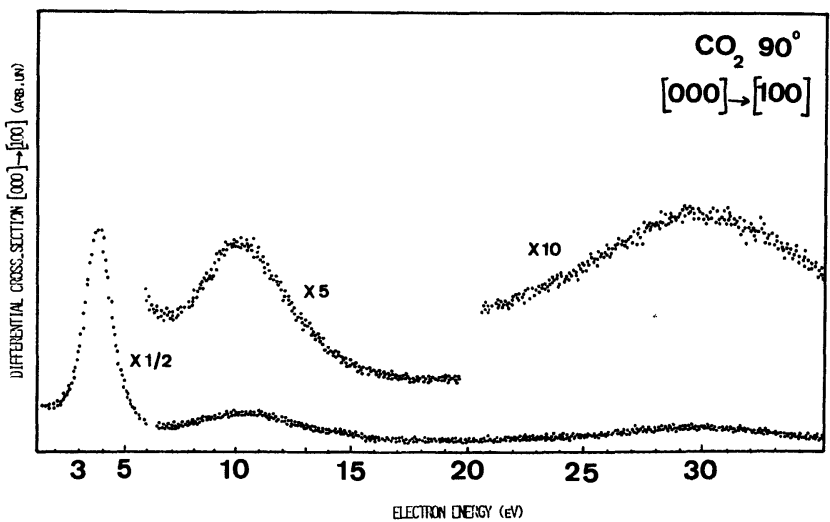

Fig. 1. - Differential cross-section for vibrational excitation of the [100] symmetric stretch mode in $\mathrm{CO}_{2}$ observed at $90^{\circ}$. 
mixture. Because of the large energy range, the transmission of electrostatic optics has been calibrated with absolute elastic cross-sections in helium $[9,10]$ between 4 and $35 \mathrm{eV}$ and for scattering angles from 30 to $120^{\circ}$.

3. Results. - Figure 1 shows the differential crosssection for exciting the vibrational mode [100] (symmetric stretch) in $\mathrm{CO}_{2}$ between 1 and $35 \mathrm{eV}$ for an angle of observation of $90^{\circ}$.

The intense peak at $3.8 \mathrm{eV}$ was recently studied in detail by Čadež and collaborators [7]. They observed oscillatory structure whose position moves towards higher energies, and whose relative intensity increases when observed in higher vibrational levels. These structures are related to the autodetaching width of the resonance being of the same order of magnitude as the separation between vibrational levels. They can be described as an interference pattern between the nuclear wavefunction and a single reflected wave on the potential barrier (boomerang model) [11]. This resonance is characterized by a dominant $l=1$ partial wave, with a small contribution of the $l=3$ wave which is observed to decrease throughout the resonance energy region [13]. Above $4.4 \mathrm{eV}$ this resonance is observed in the dissociative attachment process giving $\mathrm{O}^{-}$[12] in competition with the autodetaching process.

The broad bump centred at $10.8 \mathrm{eV}$ in figure 1 is attributed to a $\sigma_{\mathrm{g}}$ shape resonance. The width of $5 \mathrm{eV}$ (Table I) gives a lifetime as short as $1.3 \times 10^{-16} \mathrm{~s}$. This resonance was observed in excitation of the [200] vibrational mode with an intensity 5 times lower, but it cannot clearly be observed neither in the elastic cross-section, presumably because of the dominant direct process, nor in the cross-section of the bending mode [010] presumably because of its very short-lived nature. The theoretical calculations $[3,13]$ predict the $l=2$ and $l=4$ partial waves to be dominant, but with varying contribution in the resonance region as reflected in the angular distribution [15] of the [100] excitation mode. A discrepancy of $2 \mathrm{eV}$ is observed between the theoretical and experimental positions of the resonance, but it seems that the theoretical position is sensitive to the exchange approximation [14] especially at low energy.

The low intensity bump at $30 \mathrm{eV}$ is attributed to a $\sigma_{\mathrm{u}}$ shape resonance. The position is in good agreement with theoretical prediction $[3,13]$. The resonance is observed in the cross-section for exciting the [200]

$\begin{array}{cccc}\text { Table I. - Properties of } & \text { shape resonances in } \mathrm{CO}_{2} \text {. } \\ \text { Energy } & & \text { Half-width } & {[100]} \\ \text { position } & \text { Symmetry } & (\mathrm{eV}) & \frac{[200]}{[20 t i o} \\ - & - & - & - \\ 3.8 & \pi_{\mathrm{u}} & 1.2 & 1.8 \\ 10.8 & \sigma_{\mathrm{g}} & 5 & 5 \\ 30 & \sigma_{\mathrm{u}} & 8 & 7\end{array}$

vibrational mode with an intensity 7 times smaller than for the [100]. In table I we notice that when the width of the resonances increases the ratio of the crosssections $v=2 / v=1$ decreases as expected for shortlived resonances, and this supports the attribution of the 10.8 and $30 \mathrm{eV}$ cross-section enhancement to broad resonances rather than to the existence of a number of overlapping resonances. Further evidence for the existence of these resonances can be provided by inner-shell photoionization spectra [3], and the two broad features observed at $\sim 6.5$ and $17 \mathrm{eV}$ above threshold in the carbon $\mathrm{K}$-shell photoionization spectrum of $\mathrm{CO}_{2}$ [17] can be due to the same $\sigma_{\mathrm{g}}$ and $\sigma_{\mathrm{u}}$ shape resonances. The eigenphase calculations [13] predict that the $l=1,3,5$ partial waves contribute to the $\sigma_{\mathrm{u}}$ resonance. But the angular distribution of the electron having excited the [100] level in the $\sigma_{u}$ resonance energy does not allow the mixture of these three partial waves to be determined because the number of parameter is too high for the fitting procedure to have any physical significance [15].

The multiple scattering approach [3] predicts $\delta_{\mathrm{g}}$ and $\delta_{\mathrm{u}}$ shape resonances, but they are low intensities and are not observed in vibrational excitation, being weakly coupled with nuclear motion as they are not oriented along the molecular axis.

4. Conclusion. - Two new short-lived shape resonances have been observed in the vibrational excitation in $\mathrm{CO}_{2}$. The existence of such high energy shape resonances appears as a common phenomena in molecules and has already been observed in $\mathrm{N}_{2}[16,14]$, in $\mathrm{CO}$ [15] and is being looked for in diatomic molecules $\mathrm{NO}, \mathrm{O}_{2}$ and $\mathrm{HCl}$ and in polyatomic molecules $\mathrm{COS}, \mathrm{BF}_{3}$ and $\mathrm{SF}_{6}$.

\section{References}

[1] Schulz, G. J., Principles of laser plasmas, G. Bekefi, Ed. (Wiley N. Y.) 1976.

[2] Dehmer, J. L. and Dill, D., J. Chem. Phys. 65 (1976) 5327.

[3] Dehmer, J. L. and Dill, D., Electron and Photon Molecules Collisions, V. Mc Koy, T. Rescigno, B. Schneider Eds (Plenum Press, N. Y.) 1979.

[4] Tronc, M., KIng, G. C., Read, F. H., J. Phys. B 12 (1979) 137

[5] Tronc, M., King, G. C., Read, F. H., J. Phys. B 12 (1979) sous presse.

[6] Tronc, M., Huetz, A., Landau, M., Pichou, F., ReinHARDT, J., J. Phys. B 8 (1975) 1160.

[7] Čadež, I., Gresteau, F., Tronc, M., Hall, R. I., J. Phys. B 10 (1977) 3821.

[8] Simon, D., Azria, R., Tronc, M., J. Phys. B Lett. 11 (1978) 561.

[9] ANDRICK, D. and BithCh, J. Phys. B 8 (1975) 393.

[10] Mc Conkey, J. W. and Preston, J. A., J. Phys. B. 8 (1975) 63.

[11] Herzenberg, A., J. Phys. B 1 (1968) 548.

[12] Chantry, P. J., J. Chem. Phys. 57 (1972) 3180.

[13] Lynch, G., Dill, D., Siegel, J., Dehmer, J. (1979) to be published.

[14] Dehmer, J. L., Sifgel, J., Welch, J., Dill, D. (1979) to be published.

[15] Tronc, M. and Azria, R., J. Phys. B (1979) to be published.

[16] Pavlovic, Z., Boness, M. J. W., Herzenberg, A., Schulz, G. J., Phys. Rev. A 6 (1972) 677.

[17] Wight, G. R. and Brion, C. E., J. Electron. Spectrosc. 3 (1974) 191 